\title{
Apuntes sobre el rublo: la occidentalización de la moneda
}

\author{
Notes about Rublo: The westernization of the currency
}

\author{
Henry Daniel Vera-Ramírez \\ Estudiante de Doctorado en Estudios Medievales, Universidad Nova de Lisboa. \\ Docente de la Corporación Universitaria Minuto de Dios \\ y de la Universidad Colegio Mayor de Cundinamarca \\ https://orcid.org/0000-0002-3977-3073 \\ hveraramire@uniminuto.edu.co; hdverar@unicolmayor.edu.co
}

Fecha de recepción: 29 de abril del 2019

Fecha de aceptación: 6 de junio del 2019

Disponible en línea: 1 de julio del 2019

Sugerencia de citación: Vera-Ramírez, H. D. (2019). Apuntes sobre el rublo: la occidentalización de la moneda. tiempo\&economía, 6(2), 11-35

doi: http://dx.doi.org/10.21789/24222704.1500

\section{RESUMEN}

Este documento analiza algunos momentos clave en el desarrollo e historia del rublo como medio de pago, haciendo énfasis en el hecho de que su curso se ha relacionado con un proceso de occidentalización del manejo monetario, que ha permitido soslayar en varios momentos, la pérdida de poder adquisitivo y el sostenimiento de la moneda-institución. Por otro lado, desde finales del siglo XIX, el oro comienza a tener preponderancia en la economía del país y se constituye en elemento clave de generación de riqueza y apoyo a una mayor emisión. Este análisis conduce a la introducción de un punto central y es la importancia del debate sobre el papel del dinero en las bonanzas y crisis económicas y su expresión práctica en las reformas monetarias llevadas a cabo en Rusia en tiempos posteriores al colapso de la Unión Soviética; punto de inflexión y de consolidación de la aceptación del uso de la moneda en el sentido que dan de a ésta las sociedades occidentales. 
Palabras clave: rublo, historia del rublo, moneda oro, crisis económicas, medios de pago, historia económica.

Códigos JEL: B14, B24, E42, E51, N13, N14

\section{ABSTRACT}

This document analyzes some key moments in the development and history of the ruble as a means of payment, emphasizing the fact that its evolution has been related to a process of westernization of monetary management, which has made it possible to avoid, in several moments, the loss of purchasing power and the sustenance of the currency institution. On the other hand, since the end of the 19th century, gold has begun to have a preponderance in the country's economy and it represents a key element in the generation of wealth and support for greater issuance. This analysis leads to the introduction of a central point, which is the importance of the debate on the role of money in economic booms and crises and its practical expression in monetary reforms carried out in Russia in the aftermath of the collapse of the Soviet Union, the point of inflexion and consolidation of the acceptance of the use of the currency in the regard western societies give to it.

Key words: ruble, ruble history, gold coin, economic crisis, means of payment, economic history.

JEL Codes: B14, B24, E42, E51, N13, N14 


\section{Introducción}

La moneda rusa tuvo un desarrollo histórico que puede rastrearse desde la influencia de monedas de otros pueblos que ejercieron dominio en su territorio en diferentes momentos. La influencia normanda, escandinava, mongola y bizantina es innegable, incluso la moneda árabe tuvo un nivel aceptable de importancia en el desarrollo de los medios de pago de este país (Vera, 2018). La influencia multicultural es tangible en Rusia, sin embargo, en algunos aspectos implicó un proceso de homogenización, que en el plano cultural llevó a la adopción de costumbres occidentales.

Al margen de esta discusión sobre lo relativo a la cultura y que no puede abordarse extensamente en este documento, se debe tener en cuenta que existe una amalgama de factores culturales diversos provenientes de oriente medio y lejano, así como de elementos netamente occidentales que confluyen en lo que podría entenderse como eslavización y su interacción con otros elementos bizantinos que se relacionan con una iglesia ortodoxa fuerte y una figura autárquica que se encontraba en cabeza del sistema zarista.

El presente documento intenta demostrar cómo el proceso de aceptación de los estándares occidentalizados para el uso de la moneda ha generado en ciertos momentos históricos del desarrollo del país, desequilibrios monetarios de corto plazo. Y, además, cómo esto se ha venido afianzando, sobre todo en el periodo posterior a la desaparición de la Unión Soviética, como elemento estabilizador de una situación económica con consecuencias negativas provenientes del sistema del socialismo real.

De igual manera, la aceptación de estos estándares no deja de lado la discusión sobre la homogeneidad cultural; pero más allá, implica el reconocimiento de que el análisis de los hechos que estudia la historia económica pueden servir de ejemplo para garantizar el equilibrio económico, sobre todo en lo referente a la política monetaria en un Estado que debe garantizar el acceso a los medios de pago sin que se presenten problemas dramáticos de pérdida de poder adquisitivo y en el peor de los casos hiperinflación.

\section{Antecedentes históricos}

La occidentalización monetaria, iniciada con Pedro el Grande, propició una modernización de los medios de pago, bajo un esquema imperial que exigía la consecución de recursos en tiempos de economías de guerra y de expansión territorial. Esta primera etapa -exitosa hasta cierto punto- no deja de ser cuestionada por su carácter autocrático y hegemónico, sin procesos "reales" de industrialización y soportado aún en un sistema de servidumbre campesina.

Dicho proceso de occidentalización iniciado por Pedro el Grande a pesar de lo caprichosa y costosa -no sólo desde el punto de vista moral sino en vidas humanas-, propicia un momento clave para la moneda en el país, que hasta este punto, no había desempeñado un papel relativamente importante, por cuanto no fue sino hasta la consolidación del rublo como moneda nacional, que el estudio de los agregados monetarios adquirió relevancia, permitiendo medir la incidencia de la moneda en la productividad del país y, sobre todo, la influencia de la economía monetaria en la economía real. 
Si bien, se reconoce que el proceso de occidentalización financiera y del uso de la moneda fue iniciado por Pedro el Grande, este debate sobre el origen no ha sido esquemáticamente abordado aún, y se ha dado de forma independiente del debate ideológico. En este orden de ideas, el análisis realizado por Berlin (2012) sobre la cultura rusa ubica una perspectiva libertaria en contradicción con la visión -oligárquica o autocráta- del bizantinismo, visión libertaria que se sintetiza en la revisión de pensadores como Herzen y Bakunin. Afirma Berlin con respecto a Herzen:

El hombre, comúnmente se asegura, desea la libertad. Más aún, se dice que los seres humanos tienen derechos en virtud de los cuales exigen cierto grado de libertad de acción. Estas fórmulas, en sí mismas, le parecen vanas a Herzen. Se les debe dar un significado concreto, pero, aun así -se les toma como hipótesis en que la gente realmente cree- son falsas, no las confirma la historia. Y es que las masas rara vez han deseado la libertad. (Berlin, 2012, p. 173)

Esta idea que se ha afianzado en un imaginario sobre el pueblo ruso, de considerarlo como un pueblo que ha dado la espalda a la democracia liberal, idea que permea muchos de los debates políticos sobre el funcionamiento de su sociedad y el rechazo a diferentes instituciones de tipo occidental que supuestamente no podrían funcionar en este tipo de Estado. Esta perspectiva, que puede ubicarse como anti-revolucionaria o como histórico-conservadora, considera como elemento fundamental de la historiografía rusa, un aparente desdeño general por la libertad como valor supremo y se circunscribe netamente en un deseo de supervivencia y supremacía de las élites pro-zaristas y pro-imperiales. En el otro extremo, podemos encontrar a pensadores como Bakunin, de quien Berlin afirma:

Bakunin con su propio impulso, con su lógica y su elocuencia, su deseo y capacidad de socavar, incendiar y hacer pedazos, ora encantadoramente infantil, ora patológico e inhumano; con su extraña combinación de agudeza analítica y exhibicionismo incontrolable; llevado consigo, con soberbia desenvoltura, la herencia abigarrada del siglo XVIII, sin molestarse en considerar si algunas de sus ideas contradecían a otras -la dialéctica se encargaría de eso-, o cuántas entre ellas se habían vuelto caducas, o eran absurdas desde el principio, Bakunin el amigo oficial de la libertad absoluta, no nos ha legado una sola idea que valga la pena considerar por sí misma. (Berlin, 2012, p. 213)

Berlin, considera a Bakunin superfluo, poco profundo e iniciador de una perspectiva de la historia rusa que no se sometió a un escrutinio complejo de las contradicciones de la época y que no tuvo en cuenta salidas realistas y prácticas a la tensión existente entre servidumbre y zarismo, pero que, sin embargo, influyó en el análisis de la historia rusa desde el siglo XIX. Este conservadurismo llevó en épocas más recientes a lo que Trenin (2016), ha denominado un imperial revival, que se ha acompasado con la necesaria introducción de las instituciones financieras occidentales en el país, no sólo para solventar las crisis, sino para "enseñar" a las autoridades rusas acerca del manejo económico.

A pesar de que el proceso monetario de oficialización del rublo se llevó a cabo en un sistema contrario al democrático-liberal, ya que su desarrollo y consolidación se dieron en el periodo zarista en su fase imperial, se pueden ubicar elementos dentro de la historiografía rusa sobre el desarrollo monetario del país, lo que implica rastrear el origen de las diferentes unidades monetarias que se han utilizado en el transcurso histórico y que están relacionadas con 
el uso en principio del dinero-piel o dinero-cuero, la influencia del comercio ruso, y su relación con distintas etapas que se compaginan con la presencia de elementos eslavos, bizantinos, tártaros, conservaduristas, liberales y finalmente con aspectos occidentalizados ${ }^{1}$, con tendencia hacia una democracia de tipo occidental, y que introdujo el debate sobre el retorno a un imperio perdido (Seljak, 2012, p. 1).

Siguiendo a Mavor (1914) y Kluchevsky (1911), la historia de Rusia puede ser dividida en cinco grandes periodos: uno kievita, otro moscovita, otro relacionado con una confusión frente a la autoridad política y a la consolidación nacional, uno moderno y un periodo final que comprendería el proceso de consolidación de la Unión Soviética. El periodo moderno puede extenderse desde el siglo XVIII hasta el siglo XIX. Este se caracterizó por la formación de una clase militar independiente de la nobleza y la consolidación de elementos culturales propios de los pueblos eslavos que entran en contradicción con el intento occidentalizador de Pedro el Grande, mientras que en el plano económico se encuentra como eje fundamental el crecimiento industrial, principalmente en el siglo XVII.

El último periodo se extendería desde la mitad del siglo XIX hasta el final del primer cuarto del siglo XX y se caracterizaría por el crecimiento de la población y el incremento de la extensión territorial imperial. Económicamente, se observa un giro significativo al abordar a Rusia como un territorio en proceso de desarrollo sustentado en el conjunto de recursos forestales, agrícolas y mineros que provee -entre otras zonas- la región de Siberia. Además, se consolidó el sector industrial y el campesinado bajo el dominio y dependencia económica de propietarios y terratenientes, alcanzando un nivel importante de producción agrícola que se expresó en el aumento de la exportación de cereales. Este último periodo coincide con una primera fase de eventos que comienza con la guerra ruso-japonesa en el año 1904 y la revolución de 1905-1906, y una segunda fase de eventos que corresponde a la Primera Guerra Mundial, la caída de la Dinastía Romanov, el colapso imperial y el establecimiento del régimen comunista (Mavor, 1914, p. xxxiv).

Siguiendo esta línea, la época prerrevolucionaria y la conformación de la Unión Soviética generaron cambios que implicaron un nivel de análisis más profundo. Sin embargo, es importante resaltar que estos últimos periodos permitieron realizar un seguimiento al desarrollo monetario en consonancia con los logros y efectos - positivos o negativos- que tuviese dicho manejo en la economía real. Para ello, se hace importante poder describir algunos elementos teóricos sobre la influencia de la moneda en las actividades económicas de la modernidad rusa.

\section{Desarrollo de la Banca}

Para Maisiev (2012), la historia de la banca se divide en tres grandes etapas: la primera correspondería al surgimiento de la banca antes del año 1600, con base en los mecanismos de depósitos en el Mundo Antiguo, la antigua Roma y la preponderancia de los banqueros usureros de la Edad Media. Una segunda etapa se denominaría la banca libre, entre los años 16001820 , caracterizada por el auge de los bancos venecianos y los holandeses, proceso paralelo al

1 Aspectos que se relacionan con una banca central, la soberanía sobre la moneda, políticas para el control inflacionario y el control de precios, el diseño de modelos de manejo de los regímenes cambiarios y un elemento central en el análisis de las economías monetarias: la neutralidad del dinero. 
establecimiento de los bancos privados en Inglaterra. Una tercera etapa podría ubicarse entre los años 1820-1913, caracterizada por la "primera expansión bancaria" que comprendió la internacionalización de los bancos mixtos, el surgimiento del mercado de valores corporativos y la universalización del sistema de banca. En este periodo se ubica el surgimiento de la Banca Central en Rusia.

Entre los años 1960-2007 se habría dado una segunda expansión bancaria, que estuvo marcada por la reestructuración sectorial, una especialización bancaria y un aumento del crédito. Una última etapa, que inició en 2008 y que podría ir hasta 2020, se caracteriza por la restricción de las actividades bancarias, se sustenta en los acuerdos de Basilea III, con la intención de establecer limitaciones a las operaciones de inversión. El banco central de Rusia fue fundado el 13 de julio de 1990, pero su raíz histórica puede ubicarse en el Banco Estatal del Imperio Ruso de 1860-1917, que fue luego reemplazado por el Banco del Pueblo de Rusia hasta el año de 1922 y luego por el Banco del Estado de la URSS hasta 1991. Este desarrollo de la bancarización se acompasó con el desarrollo de la moneda nacional y de los medios de pago.

Hasta bien avanzado el siglo XVIII no existía en el país una institución bancaria como tal. Fue la Casa de la Moneda la que llevó a cabo las primeras operaciones de crédito entre los años 1729-1733, en el periodo del Zar Pedro II y la Emperatriz Anna loanovna. Una de las funciones de la Casa de la Moneda consistía en la adjudicación de créditos a corto plazo que estaban garantizados por oro y plata, sin embargo, el volumen de las operaciones era realmente pequeño (Maisiev, 2012, p. 380).

Un elemento que influenció el nacimiento de la banca fue la supresión de los derechos de aduana entre Ucrania y Rusia en el año 1754 (Maisiev, 2012, p. 380). En la segunda mitad del siglo XVIII creció la producción manufacturera, lo que aumentó el comercio entre ciudades y el comercio interregional, lo que implicó un aumento sustancial en el costo del transporte y, por lo tanto, en la circulación de la moneda. Para esta época aparece el concepto de banco en el imperio, bajo la emperatriz Elizabeth Petrovna en el año de 1754, junto con la primera hipoteca del Banco Estatal de la Nobleza, que en realidad se dividía en dos bancos que se ubicaron en Moscú y en San Petersburgo y cuya función principal fue la de prestar dinero a las élites, sobre la base del oro, plata, joyas y la cosecha de campesinos; en este mismo año se crea un banco de préstamos mercantiles, que concede estos sobre la base de determinadas mercancías como soporte de pago.

El proceso de creación de la banca significó un avance importantísimo en el desarrollo de la economía rusa, muy a pesar de las críticas realizadas por Lenin (1981), del problema de las cajas de ahorro, cuyo crecimiento fue importante en el periodo de 1895-1899. Lenin hizo un análisis interesante sobre el incremento del monto de lo que el revolucionario define como "ahorro popular". En cinco años, las cajas de ahorro crecieron en 1189 sucursales y los depositantes aumentaron de 1'664.000 a 3'145.000, lo que supondría una mejora significativa en las condiciones de los ahorradores. Lenin cuestiona si realmente existió una mejora en las condiciones de los campesinos, o si existió lo que se denominó concentración de ahorros monetarios. Lenin analiza, entre otras cosas, la concentración de los recursos de las cajas y deduce que el promedio de ahorro por persona en las mismas correspondía a 185 rublos. En la tabla 1 se expone la concentración de los ahorros de las cajas. 
Tabla 1. Concentración de las cajas de Ahorro en Rusia 1895-1899

\begin{tabular}{ccc}
\hline Ahorradores & Promedio de ahorros & Monto total \\
Clero & (rublos) & (millones de rublos) \\
\hline Propietarios de tierras & 333 & 46 \\
Comerciantes & 268 & 99 \\
Oficiales & 222 & - \\
Funcionarios civiles & 222 & 126 \\
Agricultura y otras ocupaciones rurales & 202 & - \\
Empleados establecimientos privados & 197 & - \\
Otras ocupaciones & 196 & - \\
Oficios urbanos & 186 & - \\
Servicio doméstico & 159 & - \\
Trabajo en fábricas & 143 & - \\
\hline
\end{tabular}

Fuente: elaboración propia sobre la base de los datos de Lenin (1930).

En términos generales, Lenin (1981) considera que los dueños del capital a quienes consideraba personas "manifiestamente ricas", constituyen 1/7 del total de los depositantes y poseen más de la mitad del capital el $54 \%^{2}$. Las cajas de ahorro, como extensión de la banca que poco a poco se consolidaba en el país, representaron un avance significativo en la monetización aún en la etapa imperial eran la expresión popular del proceso de bancarización.

\section{Rublo y comercio en los siglos XVI - XX}

Según Kirchner (1976), durante la dinastía Romanov (1613-1917), el conjunto de guerras fallidas con otras naciones generó la necesidad de emitir moneda para el tesoro; la fuerza laboral fue necesaria para el trabajo en la tierra lo que implicaba la necesidad de un salario pagado en dinero, a pesar de que la mano de obra también se obtuvo a través del intercambio de prisioneros. Los alimentos volvieron a abastecer las tiendas y el comercio revivió pero en condiciones de mayor exigencia, que generalmente estaban atadas a privilegios en precios regidos por monopolios extranjeros, privilegios que se acordaron principalmente con Inglaterra y Holanda, situación que generaba una dependencia económica (Kirchner, 1976, p. 58).

La economía del país tuvo una gran transformación a partir de las reformas introducidas por Pedro el Grande. Por ejemplo, la industria metalúrgica tuvo un incremento importante desde su época, jalonada por el hierro, el cobre y el oro, principalmente. Esto, aunado a un avance industrial significativo y a una expansión de la agricultura, permitió un aumento del comercio con mayor emisión. Las exportaciones aumentaron alcanzando en el puerto de Arcángel un valor ponderado de tres millones de rublos. Con la importancia que alcanzó San Petersburgo

2 Lenin realiza su análisis con base en el Informe sobre cajas de ahorro del Estado del año 1899, documento editado por el Estado zarista. 
como centro de desarrollo, el comercio se concentró en la ciudad con un ponderado de dos millones de rublos. El mismo monto se presentó en el puerto de Riga (Kirchner, 1976, p. 58).

El comercio anual en la mitad del siglo XVIII representaba quince millones de rublos, y a comienzos del siglo XIX alcanzaba los ciento veinte millones de rublos. Otro rubro que tuvo un incremento significativo en el desarrollo de las exportaciones rusas en esa misma época fue la exportación de granos, constituyéndose en uno de los países de mayor producción a nivel mundial. En el año de 1760 exportó setenta mil quarters ${ }^{3}$, con un valor de 822.000 rublos y ya al inicio del siglo XIX, se exportaban 2'218.000 quarters, valorados en doce millones de rublos (Vernadsky, 1930, pp. 107-108). La siguiente gráfica muestra los incrementos en la exportación de granos entre el año 1760 e inicios del siglo XIX.

Gráfica 1. Incrementos en la exportación de granos entre el año 1760 y el siglo XIX

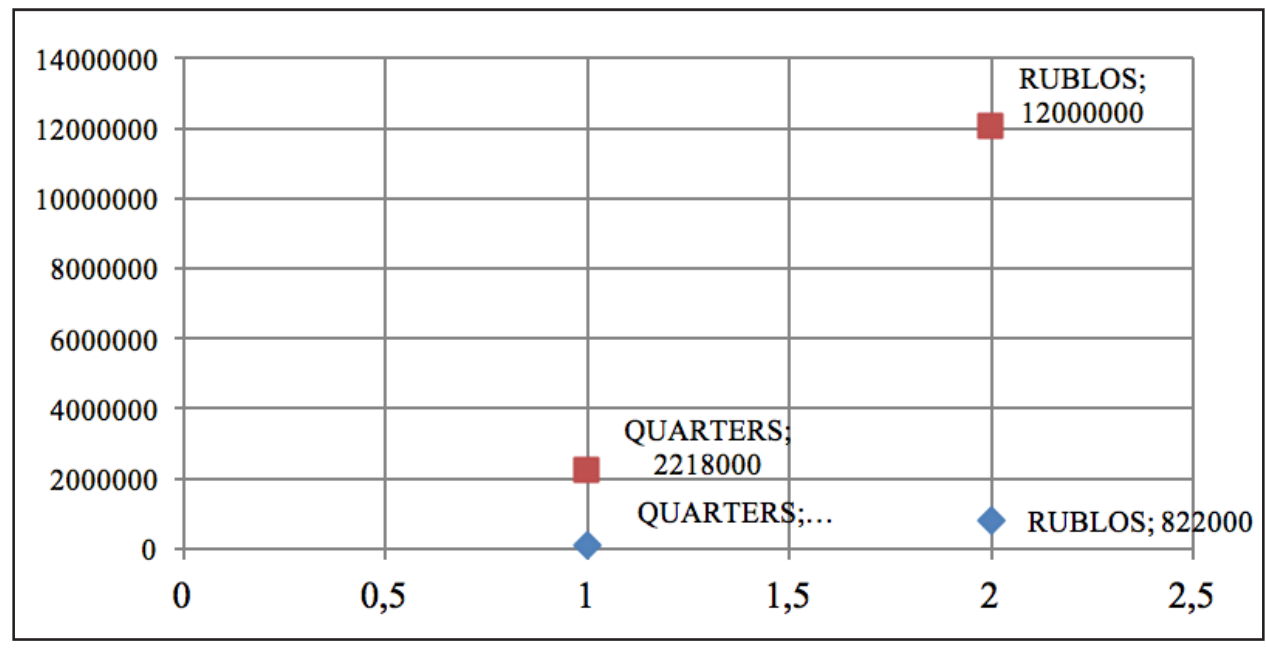

Fuente: elaboración propia sobre la base de los datos de Vernadsky (1930).

Este desarrollo implicó un aumento significativo de la emisión de dinero, que compensaba el ingreso de unidades monetarias por concepto de exportaciones, lo que aumentó el circulante de medios de pago en el país. El rublo adquiere su mayoría de edad, y se constituyó en la moneda de mayor relevancia en la Europa del Este, no sin ser víctima -incluso desde sus inicios-, de profundas crisis que han afectado su convertibilidad externa y su equivalencia interna y el uso de políticas adecuadas para sostener su estabilidad.

En este periodo, el crecimiento económico implicó mayor emisión y esto impone la necesidad de determinar políticas de manejo monetario. Podría afirmarse que la política monetaria rusa comienza a tener un relativo manejo desde el año 1769. Y desde este año hasta 1786 se sostuvo una equivalencia del rublo/kopeks, muy cercana a 100 kopeks de plata por rublo, situación que, sin embargo, presentó leves variaciones principalmente en el periodo 1772-1775. La tendencia fue a sostener una equivalencia de 99 kopeks por rublo en este periodo; dicha equivalencia, se sustenta en la forma en que tradicionalmente se han divido

3 Es una medida de cuenta que equivale en el sistema americano a 226,796185 Kg y en el sistema británico a $254,0117272 \mathrm{~kg}$. Más o menos un cuarto de tonelada. 
las unidades monetarias en muchas economías occidentales. Los kopeks presentan una equivalencia con los centavos en diferentes unidades de cuenta en muchos países occidentales (Owen, 1944, p. 703). La gráfica 2 muestra la equivalencia de rublos en kopeks de plata para al periodo 1769-1786.

Gráfica 2. Equivalencia del rublo en kopeks de plata 1769-1786

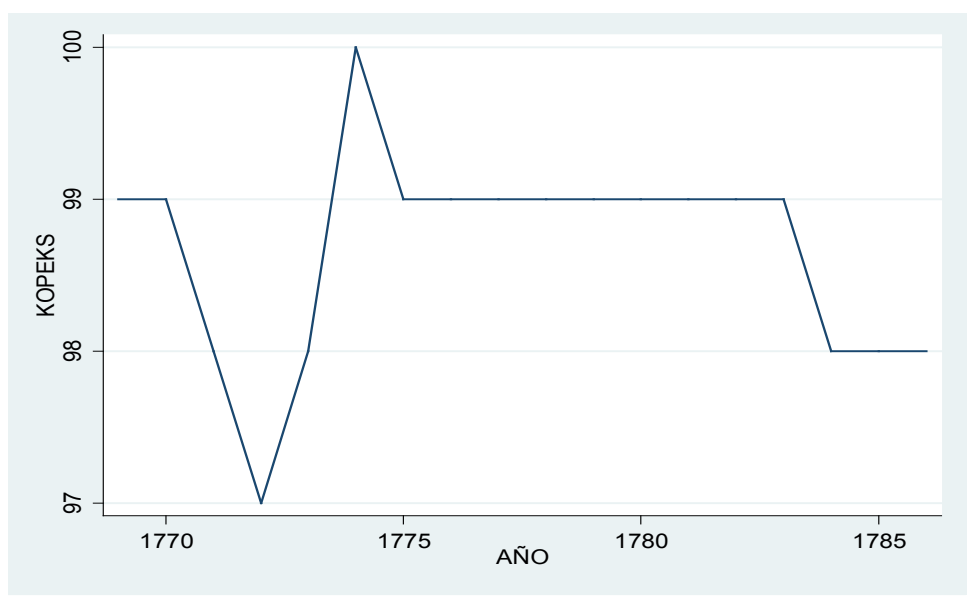

Fuente: elaboración propia sobre la base de los datos de Owen (1989).

Owen (1989) destaca la época zarista como el periodo histórico en el que comienza a establecerse un proceso de institucionalización monetaria, principalmente desde la creación del papel moneda ruso, por Catalina II la Grande en el año 1768. En la tabla 2 se presentan las etapas de manejo monetario de acuerdo con el tipo de rublo dominante: el rublo de plata, el rublo de cobre, el papel moneda y el denominado credit ruble. A este respecto, si bien el papel moneda ya circulaba desde Catalina, se observa una predilección para la época por el uso del rublo de plata. El periodo de Catalina también generó un deterioro importante en la aceptación y uso del rublo de cobre ${ }^{4}$.

Tabla 2. Tipos de Rublo y periodo de influencia

\begin{tabular}{cccc}
\hline Rublo de plata & Papel moneda ruso & Credit ruble & Patrón oro \\
\hline $1769-1852$ & $1768-1842$ & $1841-1917$ & 1897 \\
\hline
\end{tabular}

Fuente: elaboración propia con base en Owen (1989).

El papel moneda ruso tuvo una mayor influencia en el segundo periodo comprendido entre los años 1768-1842, que se acompañó de un proceso de industrialización ascendente, con el auge económico de la ciudad de San Petersburgo y la imposibilidad de sostener la emisión

4 La pérdida de valor del papel moneda ruso (assignat ruble), fue de 97,09 kopeks de plata en 1787 hasta 66,23 kopeks de plata en el año 1800. Esto equivale a una pérdida en el poder adquisitivo del papel moneda ruso del 31\%. Ver Owen (1989, p. 700). 
en plata. En este periodo también se registraron gastos excesivos generados por el Estado desde Pedro I el Grande, y por la construcción de la Venecia del báltico, la conformación de una fuerza naval y una armada nacional y el sostenimiento de guerras principalmente con Suecia para la expansión de territorios hacia Europa. La gráfica 3 muestra el movimiento en la equivalencia de rublos de plata a papel moneda, para los años 1787-1842.

Gráfica 3. Equivalencia del rublo de plata en papel moneda ruso (kopeks), 1769-1786

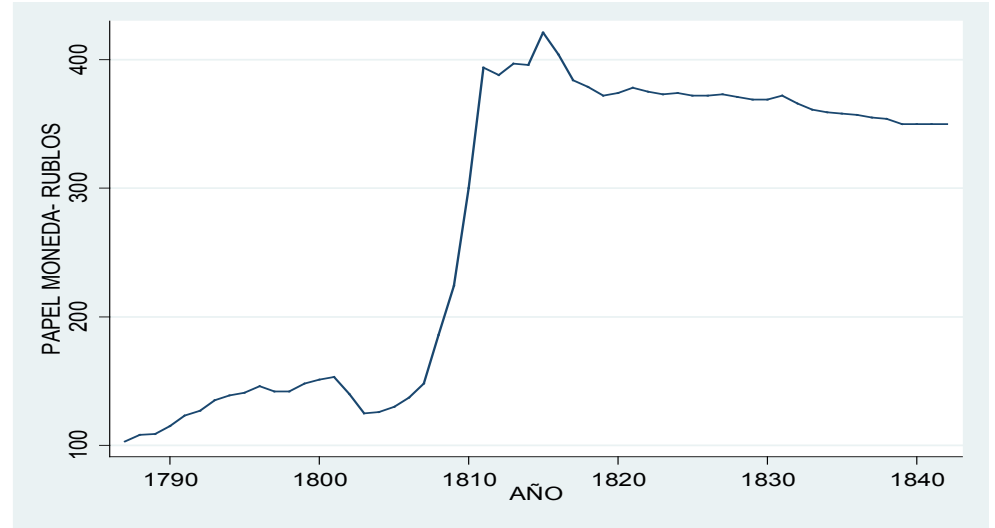

Fuente: elaboración propia sobre la base de los datos de Owen (1989).

Por otro lado, se observa para este mismo periodo la equivalencia en kopeks de plata del papel moneda ruso, con una pérdida significativa en su equivalencia desde el año 1810. El rublo de plata, presentó un periodo importante de reconocimiento por cuanto se constituyó en la unidad de cuenta entre los años 1769-1852, con el amparo de los zares Alexander I y Nicolás I. La gráfica 4 muestra el comportamiento en la equivalencia del papel moneda ruso a kopeks de plata para el periodo 1878-1842.

Gráfica 4. Conversión papel moneda ruso-kopeks de plata

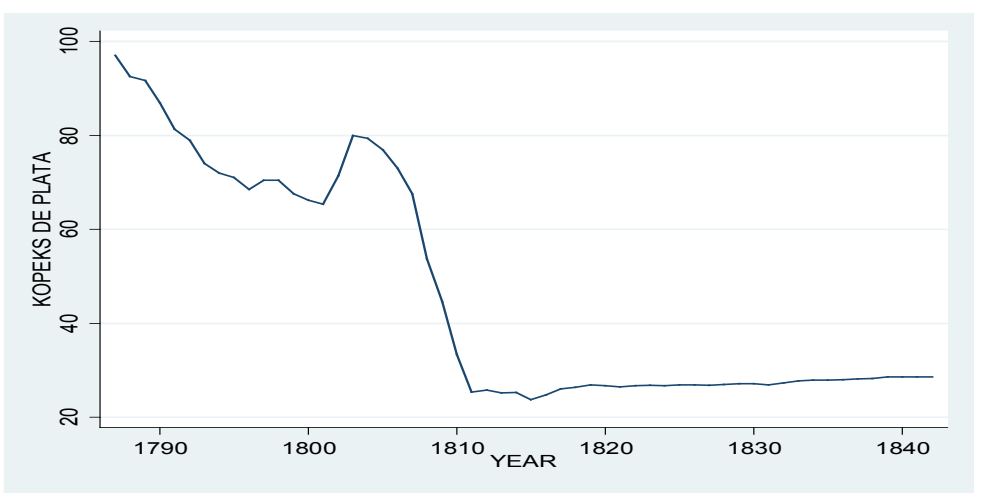

Fuente: elaboración propia sobre la base de los datos de Owen (1989).

El rublo de plata tuvo su apogeo a partir de los años siguientes a la guerra de Crimea (18531856). Generalmente una economía de guerra necesita una mayor emisión de dinero que no esté atada a algún metal, de tal manera que el credit ruble, comenzó a tener mayor influencia y 
hacia el año de 1853 presentó un nivel de equivalencia con el rublo de plata de 99,5 kopeks. La gráfica 5 muestra como este rublo comenzó a tener una mayor importancia desde el año 1850.

En estos periodos de equivalencia se pueden observar ciertos intentos de manejo monetario de una economía secularizada a la usanza occidental, con el deseo de que la moneda se oriente en su incidencia desde un organismo centralizado, sin que necesariamente se pueda hablar de independencia y autonomía del mismo; este sistema sigue siendo un sistema aún dependiente de las necesidades políticas.

Gráfica 5. Conversión del credit ruble en Kopeks de Plata 1843-1852

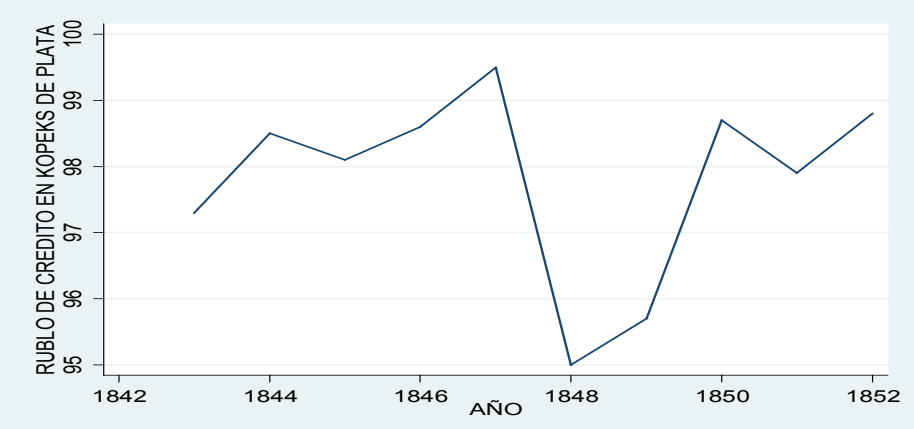

Fuente: elaboración propia sobre la base de los datos de Owen (1989).

Este sistema, sin ser eficiente, tendrá un punto de inflexión bajo la revolución decembrista. A la revolución decembrista, por ejemplo, se le atribuyó una confusión de las finanzas públicas. El rublo se depreció principalmente por la inflación, resultado de las prolongadas guerras llevadas a cabo por el zar Alejandro I. Las reformas hechas por Krankin el ministro de Finanzas, estabilizaron el precio del papel moneda en el año de 1839 a una tasa de cambio de 3,5 a 1 con respecto al antiguo rublo. El nuevo circulante se ataba a la reserva de oro y mantenía la paridad establecida, mientras que los viejos billetes fueron comprados por el tesoro del Estado. A esta crisis cambiaria sucedieron otras crisis. La tabla 3 ubica algunos periodos de desarrollo del rublo y sus equivalencias, años de crisis y/o reformas.

Tabla 3. Desarrollo del Rublo y sus equivalencias periodo moderno

\begin{tabular}{cc}
\hline Años & Equivalencia \\
\hline 1843 & Rublo de oro $=10$ rublos de plata $=1000$ Kopeks \\
1922 & Rublo $=100$ Kopeks \\
1923 & Rublo $=1000$ viejos rublos $=100$ Kopeks \\
1924 & Rublo $=100$ viejos rublos $=100$ Kopeks \\
1947 & Chernovets $=10$ rublos de oro $=500.000$ viejos rublos $=1000$ Kopeks \\
1961 & Rublo $=10$ viejos rublos $=100$ Kopeks \\
1998 & Rublo $=10$ viejos rublos $=100$ Kopeks \\
1998 & Rublo $=1000$ viejos rublos $=100$ Kopeks \\
\hline
\end{tabular}

Fuente: elaboración propia sobre los datos de Venadsky (1930), Owen (1989) y Vilariño (2001).

tiempo\&economía

Vol. 6 N. 2 - Julio - Diciembre del 2019

p. 21 
La política monetaria estableció nuevas conversiones entre la moneda antigua y la moneda nueva, siendo los periodos de conversión más fuertes: el año de 1923, cuando se establece una conversión entre el antiguo rublo y el nuevo rublo de 1 a 1000, seguido del año 1947, con una conversión de 1 a 500.000 y el año de 1998 con una conversión de 1 a 1000. Estos cambios de equivalencias se acompañaban de crisis económicas, situaciones que estuvieron a su vez ligadas a un incremento en las reservas de oro en el país, oro que se obtuvo principalmente gracias a las exploraciones entusiastamente apoyadas por el gobierno y en las que se comprometió el propio Stalin. Por otro lado, el credit ruble, comienza a perder importancia en los albores de la revolución rusa, precisamente por la inestabilidad económica y la lucha por el poder. En la gráfica 6 se muestra la relación existente entre el poder adquisitivo del credit ruble en el periodo anterior a la revolución rusa ${ }^{5}$.

Gráfica 6. Pérdida de poder adquisitivo del rublo de crédito 1913-1921

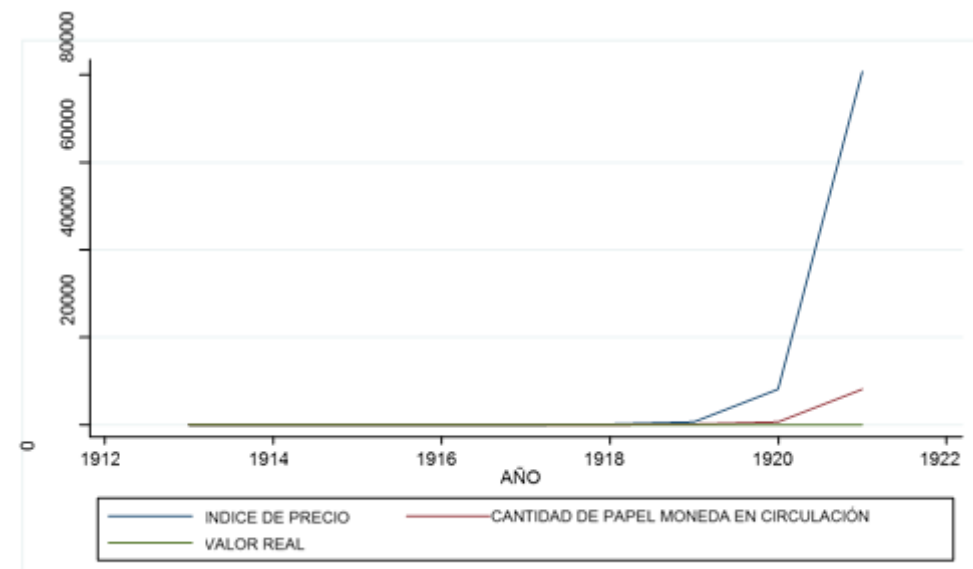

Fuente: elaboración propia sobre la base de los datos de Owen (1989).

Se observa como desde la segunda década del siglo pasado la emisión de dinero aumentó significativamente, así como el índice de precios expresado por Owen, no así el nivel o valor real del rublo, ya que, en términos reales, representó un valor relativamente estable a través de estos años. ¿Qué pudo haber permeado esta pérdida de valor en la moneda?, probablemente los hallazgos de oro y el anclaje de la misma moneda a este patrón, otra estrategia propia del manejo monetario de las economías occidentales, el Gold standard, es una herramienta monetaria propia de las economías occidentales. Otro de los elementos importantes en el proceso

5 Los datos relacionados con la indexación de precios, la cantidad de papel moneda en circulación y su valor real o deflactado, se encuentran en la siguiente tabla.

\begin{tabular}{lcc}
\hline & Media & Desviación Estándar \\
Índice de precio & 9.956 .563 & 26662.22 \\
Cantidad de papel moneda en circulación & 9.997 .222 & 2.666 .473 \\
Valor real & 2.215 & 1.998 .406 \\
\hline
\end{tabular}

El papel moneda circulante aumentó significativamente en este período con un promedio de más de nueve millones de rublos emitidos, pero su valor real es de 2 millones de rublos. Los datos se obtuvieron de las tablas propuestas por Owen (1989). 
de consolidación de la moneda rusa, puede relacionarse con la tasa de cambio frente a la moneda norteamericana. Más allá de los debates surgidos en el terreno ideológico, desde el año de 1917 el rublo comenzó a devaluarse, hasta que en el año 1958 el secretario general del partido comunista, Nikita Kruschev, propone una paridad frente al dólar de 1,5 dólares por rublo. La tasa de cambio con respecto al dólar desde 1960 hasta la década de 1990, estuvo relativamente estable. La devaluación posterior, consecuencia de la caída del sistema de repúblicas soviéticas, se puede ver en las gráficas del anexo.

\section{Importancia del oro}

En Rusia la industria minera del oro ha tenido una historia de aproximadamente trecientos años. En las minas de Nerchinsky en el año de 1702, se realizó el vertimiento del primer lingote de oro. Según Pikhoya (2003) director ejecutivo en GV Gold, cerca de 16,2 mil toneladas de oro se han extraído del país en los periodos correspondientes al imperio, la extinta Unión Soviética y la existencia de la Federación Rusa. Según el mismo autor esto equivale al 11,3 de la cantidad total de oro extraído del mundo.

Los hallazgos de oro en los Urales tuvieron una incidencia importante en la Rusia del siglo XIX, pero fue aprovechado sobre todo por los terratenientes en detrimento de los siervos. Se puede datar el renacimiento de la minería rusa en el año de 1744, con el cuarzo proveniente de Ekaterimburgo. Este hallazgo generó un estímulo a los zares para emprender mayores exploraciones de metales, teniendo en cuenta que el oro de Ekaterimburgo pasó a manos de la administración imperial y que esta mina produjo 2,6 toneladas. Fue durante el imperio del Zar Alejandro I que se creó una comisión para reglamentar la explotación aurífera. Entre 1823 y 1830, la producción en los Urales se triplicó, pasando de 1,5 toneladas a 5,4 toneladas. Las zonas tradicionales de mayor producción son Magadan, Krasnoyarsk, Yakutia, Irkutsk, Khabarovsk y la región de Amur (Green, 1980, pp. 30-31).

El oro se embarcaba desde Ekaterimburgo hasta San Petersburgo, donde se analizaba. El crecimiento observado alentó nuevas expediciones auríferas principalmente al este en las montañas de Altai, donde se explotaban un mínimo de 58 depósitos auríferos en Siberia, con una producción de 11 toneladas. Las cifras aumentaron de forma significativa de tal manera que en el año de 1847, Rusia explotaba las 3/5 partes del oro mundial. Sin embargo, la explotación aurífera en Rusia perdió relevancia por los hallazgos en California y en Australia. A pesar de ello, hallazgos en el siglo XIX en zonas cercanas al Río Lena, lago Baikal y Río Amur en la Frontera con Mongolia, generaron aumentos importantes de la producción. Este oro es importante por cuanto contribuía directamente a las opciones estatales de emisión de dinero en un Estado donde cada vez se hacía más necesario el uso de un medio de intercambio.

En muchos casos las reservas de oro fueron aprovechadas por los diferentes ejércitos en los conflictos internos, como en agosto de 1918, cuando la lucha interna entre este y oeste en Rusia se extendía a lo largo de los ríos Volga y Kama. En un principio las fuerzas de Samara obtuvieron algún éxito en la ocupación; para este caso se aprovecharon las reservas de oro del Banco del Estado de Rusia por un monto de USD \$317’000.000 (Vernadsky, 1930, p. 264). 
La economía que había colapsado en 1917 no podía reaccionar bajo condiciones financieras poco propicias. Cada año de guerra contribuía a minar el presupuesto, con la revolución los precios aumentaron y el gobierno provisional deshizo el subsidio a la industria, disminuyendo la productividad y generando una posición deudora en la balanza de pagos. En Donetsk, el subsidio fue de un millón de rublos, el pago a los soldados fue de 500.000 rublos. El incremento a los empleados de los ferrocarriles excedió 350 millones de rublos ${ }^{6}$. El alivio a las esposas de los soldados fue por once mil millones de rublos. Este amplio incremento en el gasto público significó, además, bajos niveles de ingreso para el gobierno. Las tasas de interés generales cayeron un tercio en el primer mes de revolución y en las ciudades, las tasas de interés cayeron un 43\%. Ante el déficit se aumentó la emisión de moneda -que devaluó el rublo-, además de una reforma para igualar los precios (Kirchner, 1976, p. 299).

Ante el triunfo de la revolución, las condiciones económicas y la situación por ende del rublo, tuvo un cambio dramático. La consolidación del Estado Soviético fue acompañada por una centralización autocrática y para este propósito, el sistema impositivo y de recaudo fue revisado junto a los niveles de impuestos que aumentaron significativamente: "A un alto impuesto a las ventas se sumaron las cuotas de los impuestos internos sobre sal y los impuestos regulares sobre el capital que a veces equivalían al 20\%" (Kichner, 1959, p. 59).

Se promulgaron estrictos edictos para sostener el recaudo, castigando a quienes intentaban eludir los pagos. A diferencia de Francia y España, donde el oro y las joyas fueron usados como mecanismo para incrementar el crédito nacional, en Rusia fueron inutilizados y se anquilosaron en palacios e iglesias. El año 1922, trajo consigo una reforma monetaria que buscaba la estabilización de la moneda a través del chernovets, garantizando la emisión de dinero con $25 \%$ en reserva de lingotes de oro. Dos años después, el chernovets se reemplazó por el rublo que se fijó a una tasa de una décima parte de un chernovets. El rublo se mantuvo artificialmente estable y se ancló en 1936 a una tasa de 19 centavos americanos, cayendo después de la segunda guerra mundial a 25 centavos por rublo. Varios commodities fueron utilizados como garantía de valor y la tasa de interés que se encontraba en 1929 entre 8 y 9\% disminuyó en 1940 a un valor entre $3 \%$ y $5 \%$, situación que fue acompañada por un aumento significativo del presupuesto público (Kirchner, 1959, p. 238).

El presupuesto se incrementó de manera espectacular entre los años 1922-1947, sobre todo gracias a las reformas implementadas durante el periodo post-revolucionario y post-guerra, además de un aumento importante en el nivel de producción e industrialización en el país. Para Kirchner (1959, p. 300), luego de la segunda guerra mundial, los instrumentos de política económica determinaron la organización del gobierno soviético, impidiendo el contacto con fuerzas foráneas y poderes externos que pudieran afectar su política interna. Después de la exitosa reforma monetaria de diciembre de 1947, donde el rublo -sobre la base de un sistema exitoso en muchos aspectos- se vio beneficiado por una nivelación de precios, reduciendo de

6 Según Owen (1989), las extraordinarias demandas impuestas a la red ferroviaria relativamente subdesarroIlada junto a la mejorada infraestructura industrial durante la Primera Guerra Mundial precipitaron el colapso de la economía rusa, una condición previa esencial para el derrocamiento tanto del régimen zarista como del Gobierno Provisional en 1917, y la consolidación del poder bolchevique en la Guerra Civil (1918-1920). Con esta crítica situación económica, el destino del rublo bajo el gobierno bolchevique se convierte en un tema atractivo para el historiador económico, ya que el rublo soviético comienza a perfilarse como una especie de unión monetaria también a la usanza occidental. 
manera significativa la inflación y aumentando el output agrícola y el poder de compra de las diferentes ciudades.

El impulso a la industria aurífera estuvo en cabeza de Stalin, que ya desde la década de 1920 sentía resquemor por la influencia japonesa en la zona de Siberia, lo que implicaba la consolidación de una estrategia que económicamente pudiese atraer la mano de obra rusa a estas zonas lejanas. Por otro lado, como lo reconoce Green (1983), Stalin sentía una aparente fascinación por el proceso de colonización del oeste americano por la fiebre del oro y particularmente por la tarea realizada por Bret Harte al mando de ésta. Stalin creó en 1927 la Glavsoloto o trust del oro y encomienda su manejo a Serebrovsky, jefe de la industria petrolera rusa. En un principio, las intenciones rusas estaban enfocadas en abrir un mercado minero basado en oro, para trasladarse luego a otros materiales mineros como el carbón y el hierro (Green, 1983, p. 84).

Los hallazgos de oro, realizados por Kuzmin, generaron una fiebre entre los años de 1923 y 1925, en la ciudad de Nazametny en el río Aldan, lo que movilizo a 12.000 mineros hacía la zona. El deseo de Stalin de atesorar oro, contradecía las ideas de Lenin sobre el papel del oro en la economía. En un texto que escribe Lenin en 1921, "la importancia del oro ahora y después del socialismo", afirmaba que en el capitalismo el oro tenía una importancia fundamental, pero en el socialismo perdería su valor y sólo serviría para "adornar las paredes". Esta visión no era compartida por Stalin, quien comprendía perfectamente la importancia del atesoramiento en un contexto económico regido por un sistema de patrón oro, en el que se anclaban las divisas a este metal y que tenía relación directa con la estabilidad de la moneda nacional (Green, 1983, p. 85).

El monopolio que tuvo el Estado sobre este bien dio paso a procesos de privatización que comenzaron en la década de 1990 luego del colapso soviético. Luego de esta privatización se generó el fenómeno de la ampliación de asociaciones de pequeños productores (más o menos 600), cuya característica básica ha sido la poca preparación y el mal equipamiento. En el largo plazo, estos pequeños productores no tuvieron acceso a crédito y recursos financieros, situación que aunada a la devaluación de la moneda en el año 1998 se sumó a la expansión de bancos nacionales que recibían depósitos aluviales, los cuales perdieron su rentabilidad en un $60 \%$.

\section{La división del dinero en Rusia}

La división del dinero se hace cada vez más compleja e implica el reconocimiento de otras formas de fragmentación que se suceden dependiendo de las condiciones históricas. Para el caso de Rusia, la división no presenta significativas diferencias, con respecto a las sociedades occidentales. Por ejemplo, los agregados monetarios deben reconocer no sólo la moneda de curso legal y su uso común sino otro conjunto de formas de expresión monetaria. En la tabla 4 se presenta la división de los agregados monetarios que hace Bain y Howells (2009) para tres importantes zonas del mundo. 
Tabla 4. División de los agregados monetarios

\begin{tabular}{|c|c|c|}
\hline Estados Unidos & Reino Unido & Eurozona \\
\hline $\begin{array}{c}\text { Moneda fuera de los Bancos de la } \\
\text { Reserva Federal + depósitos ban- } \\
\text { carios en los Bancos de la Reserva } \\
\text { Federal. }\end{array}$ & $\begin{array}{l}\text { Notas, moneda y reservas: moneda } \\
\text { fuera del banco de Inglaterra }+ \text { de- } \\
\text { pósitos bancarios operativos con el } \\
\text { banco de Inglaterra. }\end{array}$ & $\begin{array}{c}\text { Mo: Moneda fuera de los bancos } \\
\text { centrales nacionales + depósitos } \\
\text { bancarios con bancos comerciales } \\
\text { nacionalizados. }\end{array}$ \\
\hline $\begin{array}{l}\text { M1: Moneda en circulación + de- } \\
\text { pósitos en cheque + cheques viaje- } \\
\text { ros + "Now" depósitos. }\end{array}$ & $\begin{array}{l}\text { M4: Moneda en circulación + de- } \\
\text { pósitos a la vista y depósitos a la vis- } \\
\text { ta del sector privado no bancario en } \\
\text { bancos y sociedades inmobiliarias. }\end{array}$ & $\begin{array}{c}\text { M1: Moneda en circulación + } \\
\text { depósitos a la vista. } \\
\text { M3: M1 + Depósitos a plazo + fondos } \\
\text { del mercado monetario + letras y bo- } \\
\text { nos con menor vencimiento residual. }\end{array}$ \\
\hline
\end{tabular}

Fuente: elaboración propia sobre la base de los planteamientos de Bain y Howells (2009).

Con respecto a Rusia, se puede afirmar que se utilizan estas cuatro unidades: $M_{\sigma^{\prime}} M_{1}, M_{2}$ y $M_{3}$. La oferta monetaria agregada para el $M_{0}$, incluirá el efectivo en circulación, generalmente billetes y monedas y los saldos en efectivo de empresas, organizaciones y el sector productivo. Según datos de Zhukov (1993) y Dolan (1976), el dinero metálico ha equivalido a más o menos el 2-3\% del total del dinero en efectivo. Las diferencias entre el valor nominal y el valor real de la moneda implica el uso de aleaciones más baratas reduciendo el costo de producción. El $M_{1}$, para el caso del país, consiste en el $M_{0}$ más los fondos en la cuenta de las personas jurídicas y los fondos de las compañías de seguros, sumado a su vez con los depósitos a la vista de bancos comerciales. Estos saldos podrán estar a disposición de los inversores en determinados momentos. La oferta de dinero -en sentido estricto- se relaciona con el cálculo del $M_{1}$.

Los cuasidineros, como el $M_{1}$ y el $M_{3}$, representan activos financieros que no funcionan como medio de circulación, pero pueden constituirse en cuentas de efectivo. El $M_{3}$ consiste en el $M_{1}$ más los depósitos de bancos comerciales y los títulos públicos a corto plazo; los títulos públicos a corto plazo, cuyo garante es el Estado, proveen liquidez y presentan un vencimiento rápido, acompañados de una alta fiabilidad en el mercado de bolsa.

\section{La caída de la URSS y las crisis capitalistas}

La llegada del siglo XX de por sí compleja en la realidad de la Rusia zarista y el cambio generado en el tránsito hacia un sistema de naciones socialistas, fomentó una nueva perspectiva en el análisis de la moneda, por cuanto significó la adopción de las recetas de manejo occidental y una reorientación hacia un sistema que puede definirse como de unión monetaria, como en la zona europea. El rublo soviético, como ha analizado Dabrowski (1995a, 1995b, 2016a, 2016b), representó una moneda común para los países socialistas, que, desde el año de 1961, intentó mantener una paridad cambiaria con la libra esterlina y una equivalencia de 1 rublo por 0,98 gramos de oro. 
El colapso de la moneda en el bloque soviético puede explicarse, a partir de ideas como la de los choques asimétricos idiosincráticos. Debido a la presencia de determinados recursos en las repúblicas se generó una situación en la que la riqueza generada por algunas de ellas, tuviese que sostener los reveses económicos de otras.

Esto, sumado a una estructura inflexible en materia cambiaria, sólo podría representar para la población de la zona de influencia dos salidas: la movilidad del mercado laboral y del capital, y las transferencias fiscales de una zona a otra?

La URSS fue un país relativamente vulnerable a este tipo de choques a partir de tres causas referenciadas por Dabrowski: tamaño del territorio, excesiva planificación centralizada y una especialización concentrada en los territorios. Sumado a esto, se observaba un sobredimensionamiento de la producción con bienes poco competitivos con respecto al mercado internacional. La respuesta del gobierno centralizado fue paquidérmica y terminó en la intención de fortalecer una movilidad de los factores internos que se hacía más difícil por una infraestructura de transporte costosa e ineficiente.

La segunda salida propuesta, la de las transferencias fiscales, fungió como salida a las crisis provocadas por las asimetrías. Un ejemplo que propone Orlowski (1993) tiene que ver con el mercado del petróleo en la década de 1970. Los aumentos significativos en los precios del petróleo en la década de 1990 generaron un ingreso importante de recursos principalmente en tres de las repúblicas: la Federación Rusa, Turkmenistán y Kazajistán. A pesar de ello, el gobierno decidió mantener los precios internos de la energía en su nivel anterior, lo que aumentó el monto de las transferencias fiscales inter-repúblicas hasta el año de 1993, cuando el gobierno de Rusia y el Banco Central tomaron la decisión de no seguir enviando estos recursos, decisión que tuvo como consecuencia la desaparición del área de influencia del rublo soviético. La tabla 5 muestra la aparición de las nuevas unidades de cuenta en las antiguas repúblicas soviéticas.

Sin embargo, luego de la caída de la unión soviética, en Rusia surgió una nueva especie de funcionamiento económico que fue determinado por el proceso de transición, con precios que de acuerdo con Pla (2003), siguieron siendo ficticios, mientras que los salarios fueron anunciados, pero no pagados, lo que generó una economía de trueque o barter, que desestimuló el uso de la moneda. Pla, distingue entre varios tipos de trueque: directo o bilateral o conocido como mercancía-mercancía y el indirecto o multilateral en el que se distingue un esquema de mercancía-mercancía-mercancía. Sin embargo, como reconoce la misma autora, el trueque disminuyó de manera significativa desde 1998, debido a la adaptación del aparato productivo al nuevo esquema de mercado y la urgencia del uso de la moneda. En épocas recientes, Rusia ha presentado un conjunto de crisis financieras que se han visto representadas en pérdidas del poder adquisitivo de la moneda.

7 Los trabajos de Mundel (1961) sobre la teoría de un área de moneda óptima y de McKinnon (1963), proporcionan el soporte teórico para el análisis del funcionamiento eficiente de estas zonas.

tiempo\&economía

Vol. 6 N. ${ }^{\circ} 2$ - Julio - Diciembre del 2019

p. 27 
Tabla 5. Nuevas unidades de cuenta tras la caída de la URSS

\begin{tabular}{|c|c|c|c|}
\hline País & $\begin{array}{l}\text { Fecha de separación } \\
\text { definitiva de la zona } \\
\text { de influencia del rublo }\end{array}$ & $\begin{array}{l}\text { Nombre de la } \\
\text { nueva Unidad de } \\
\text { Cuenta }\end{array}$ & Observaciones \\
\hline Estonia & $06 / 22 / 1992$ & Corona & Anclado al marco alemán. \\
\hline Letonia & 07/20/1992 & Lats & $\begin{array}{l}\text { Rublo letón (rublis) al principio, reemplazado } \\
\text { gradualmente por Lats (desde marzo de 1993). }\end{array}$ \\
\hline Lituania & 10/01/1992 & Litas & $\begin{array}{l}\text { Talonas al principio, reemplazado en junio de } \\
1993 \text { por Litas; anclado partir de abril de 1994, } \\
\text { con vinculación al dólar US. }\end{array}$ \\
\hline Ucrania & $11 / 11 / 1992$ & Karbovanéts & $\begin{array}{l}\text { Reemplazado con Hryvna en septiembre de } \\
1996 .\end{array}$ \\
\hline Bielorusia & Noviembre de 1992 & Rublo bieloruso & $\begin{array}{l}\text { El rublo soviético fue aceptado hasta julio de } \\
1993 .\end{array}$ \\
\hline Kirguistán & 05/15/1993 & Som & \\
\hline Georgia & $8 / 02 / 1993$ & Kupon & \\
\hline Turkmekistán & $11 / 01 / 1993$ & Manat & \\
\hline Kazajistán & $11 / 15 / 1993$ & Tenge & \\
\hline Uzbekistán & 11/16/1993 & Som & \\
\hline Armenia & $11 / 22 / 1993$ & Dram & \\
\hline Moldovia & $11 / 29 / 1993$ & Leu & $\begin{array}{l}\text { Antes, en julio de 1993, el Kupón moldavo se } \\
\text { convirtió en moneda nacional de facto. }\end{array}$ \\
\hline Azerbaiyán & 12/11/1993 & Manat & \\
\hline Tajikistán & May-95 & Rublo tayiko & Reemplazado con Somoni en octubre de 2000. \\
\hline
\end{tabular}

Fuente: elaboración propia con base en Dabrowski (2016b).

La situación de descalabro monetario luego de la caída de la URSS fue acompañada por la crisis de no pago del gobierno ruso en 1998. En agosto de este año, el gobierno ruso no hizo los pagos de algunos bonos en manos de inversionistas extranjeros. Este default del gobierno ruso implicó la pérdida de confianza en la deuda emitida por todos los países de mercados emergentes, incluidos Brasil, Argentina, Turquía y Tailandia. En el año 1998, precisamente el 17 de agosto, el Banco Central de Rusia tomó decisiones en tres grandes temas: inversores no residentes, tipo de cambio y deuda pública. En la tabla 6 se exponen las medidas tomadas por el Banco Central.

Tabla 6. Medidas de política monetaria

\begin{tabular}{ccc}
\hline Primera medida & Segunda Medida & Tercera Medida \\
\hline $\begin{array}{c}\text { El Banco Central de Rusia siguió una } \\
\text { política que buscaba desvincular el rublo } \\
\text { del dólar, para evitar la inflación, obligan- } \\
\text { do a mantener el precio del tipo de cam- } \\
\text { bio en bandas. }\end{array}$ & $\begin{array}{c}\text { Se establecieron controles } \\
\text { itales en el corto plazo. }\end{array}$ & $\begin{array}{c}\text { Se declaró una moratoria de } 90 \text { días } \\
\text { para el pago de deudas privadas, de } \\
\text { bancos y de empresas fundamental- } \\
\text { mente a los no residentes. }\end{array}$ \\
\hline
\end{tabular}


Se decidió también extender el vencimiento de los títulos públicos expedidos en rublos que se denominaron GKO (Gosudarstvennoye Kratkosrochnoye Obyazatyelstvo) de corto plazo y los denominados OFZ (Obligatsyi Federal'novo Zaima), que van hasta los cinco años, cuyo vencimiento estuviese antes del año 1999. Esto ante la crisis presentada en los balances de las entidades financieras que colapsaron principalmente en junio de 1998.

Tabla 7. Balance de las entidades financieras en Rusia, junio de 1998

\begin{tabular}{cccc}
\hline Activo & $\%$ & Pasivo & $\%$ \\
\hline Activos exteriores & 11,6 & Capital & 25,1 \\
Activos públicos & 33 & Préstamos divisas & 16,9 \\
Créditos sector privado* & 40 & Depósitos divisas & 12,4 \\
Otros activos & 15,4 & Depósitos rublos & 21,8 \\
& & Otros préstamos & 23,8 \\
\hline
\end{tabular}

* Préstamos sin rendimiento, sobre el total de préstamos 16,4\%.

Fuente: elaboración propia con base en Vilariño (2001).

Como se observa, en términos porcentuales sobre el total de activos y pasivos agregados, la solvencia del sistema bancario era endeble con niveles de endeudamiento relativamente altos, en especial en capital y otros préstamos que representaban el $48,9 \%$ del pasivo. Por otro lado, los créditos del sector privado significaban la mayoría del activo de los balances de las instituciones financieras. Esta crisis bancaria puede haberse propiciado por la proliferación de bancos ya que en el año de 1991, existían 1350 y tres años después la cifra llegó hasta 2400, muchos de ellos se creaban artificialmente buscando obtener financiación por parte del banco central (Vilariño, 2011, p. 87). Para esta época el déficit público era de cero, bajo el supuesto de que no se contabilizan los intereses, pero si estos se estiman, el déficit podría ser del $40 \%{ }^{8}$.

8 Según Vilariño (2001): "Otra vía de financiación del déficit público fue la concesión de créditos por el FMI, a partir de la aceptación por parte del gobierno de Rusia de los principios del organismo internacional" (p. 84). Para Malki (1999), la ratio de la deuda sobre el PIB, puede obtenerse de la siguiente manera:

Donde:

$$
b_{t}=\frac{1+r}{(1+\pi)(1+g)} b_{t-1}+d f_{t}+k
$$

$r=$ Tipo de interés nominal

$\pi=$ Tasa de inflación

$g=$ Tasa de crecimiento económico en términos reales.

$d f=$ déficit público sin intereses.

$k=$ Parámetro que depende de

Bajo determinados casos si el numerador $1+r$, es superior al denominador $(1+\pi)(1+g)$, la denominada senda de ratio de la deuda pública sobre el PIB, se considera explosiva. Es decir, que lo más aconsejable sería mantener tipos de interés nominal bajos, con una baja inflación, pero con tasas de crecimiento económico relativamente altos, pero el caso para Rusia, implicaba un comportamiento de dichas variables totalmente adverso, lo que implicó un aumento significativo en esta ratio entre deuda pública y PIB. 
La situación del país fue insostenible, lo que generó un conjunto de reformas que implicó efectos sobre la producción y en especial sobre el poder adquisitivo de la moneda. La tabla 8 y la gráfica 7 muestran la relación entre PIB, su tasa de crecimiento y la inflación entre los años 1992 y 2009.

Como puede observarse, en los años de tránsito a la adopción de medidas que involucraban la aceptación del sistema de libre mercado, la variación del PIB cayó entre el periodo de 1993-1998, con una leve recuperación del 1,4\% en el año 1997. La crisis se repitió de nuevo en el año 2009, con una caída del producto en casi ocho puntos porcentuales. La hiperinflación fue la característica en el periodo 1992-1995 llegando en el año de 1992 a un aumento de 874,62 . La reducción de la inflación a un dígito -medida comúnmente relacionada con la denominada target inflation, de los bancos centrales occidentales- sólo se logró en los años 2006 y 2007 y se mantuvo en el año 2009, muy a pesar de la caída en la producción.

Tabla 8. Relación PIB Constante, Variación del PIB y tasa de Inflación Anual en Rusia 1992-2009

\begin{tabular}{|c|c|c|c|c|c|c|}
\hline Año & PIB & $\begin{array}{l}\text { Constante Millardos } \\
\text { de Rublos }\end{array}$ & $\mathrm{PIB}$ & $\begin{array}{l}\text { Variación } \\
\text { Anual }\end{array}$ & $\%$ & Tasa de Inflación Anual \\
\hline 1992 & & 25500442 & & - & & - \\
\hline 1993 & & 23281903 & & $-8,70$ & & 874,62 \\
\hline 1994 & & 20325102 & & $-12,70$ & & 307,63 \\
\hline 1995 & & 19491772 & & $-4,10$ & & 197,47 \\
\hline 1996 & & 18790069 & & $-3,60$ & & 47,74 \\
\hline 1997 & & 19053130 & & 1,40 & & 14,77 \\
\hline 1998 & & 18043314 & & $-5,30$ & & 27,68 \\
\hline 1999 & & 19198086 & & 6,40 & & 85,74 \\
\hline 2000 & & 21117894 & & 10,00 & & 20,78 \\
\hline 2001 & & 22194907 & & 5,10 & & 21,46 \\
\hline 2002 & & 23238068 & & 4,70 & & 15,78 \\
\hline 2003 & & 24934447 & & 7,30 & & 13,67 \\
\hline 2004 & & 26729727 & & 7,20 & & 10,89 \\
\hline 2005 & & 28440429 & & 6,40 & & 12,68 \\
\hline 2006 & & 30630342 & & 7,70 & & 9,68 \\
\hline 2007 & & 33111400 & & 8,10 & & 9 \\
\hline 2008 & & 34965638 & & 5,60 & & 14,1 \\
\hline 2009 & & 32327433 & & $-7,55$ & & 8,8 \\
\hline
\end{tabular}




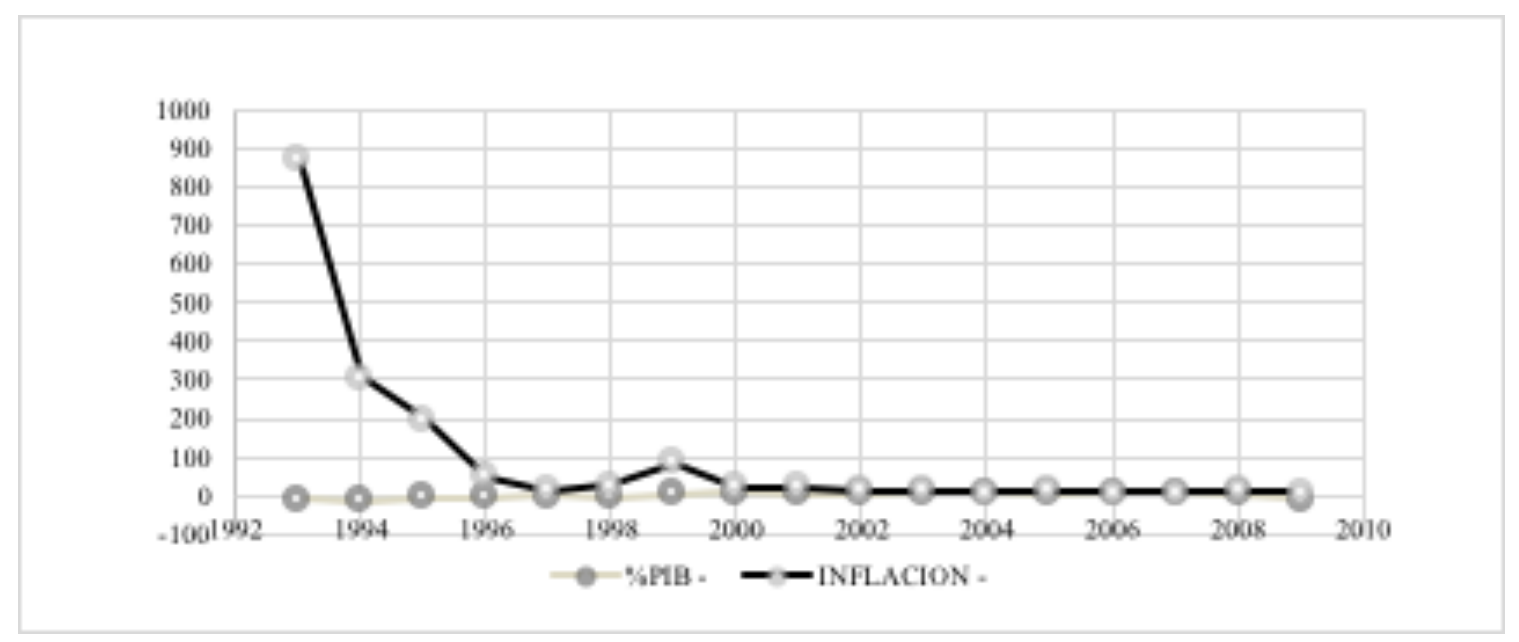

Gráfica 7. Relación incremento del PIB-Inflación Rusia, 1992-2009

Fuente: elaboración propia sobre los datos del FMI.

Las consecuencias de la crisis de la década de 1990 se observaron principalmente en la interrupción de los capitales financieros, mientras que la deuda de los bancos, de las empresas y del gobierno que estaba nominada en divisas, aumentó de manera significativa; por otro lado, se paralizó el sistema de pagos interbancario, junto a la caída de la bolsa de valores, mientras que el sector real tuvo una caída importante, principalmente el sector industrial en un 15\% con una tasa de inflación del 120\% en agosto de 1999 y una crisis bancaria sin precedentes.

\section{Conclusiones}

Es importante reconocer que la historiografía rusa no se ha centrado específicamente en el desarrollo de la moneda, como elemento sustancial dentro del desarrollo económico de la nación. De hecho, el nacimiento de la moneda nacional estuvo retrasado con respecto al nacimiento de otras monedas en diferentes países de Europa, teniendo como elemento sustancial, la influencia que tenían otras monedas como las de origen árabe e incluso la moneda bizantina. Sin embargo, en la modernidad y sobre todo a partir de las reformas de Pedro el Grande se puede apreciar un resurgimiento del interés por el análisis de la moneda, como elemento sustancial del desarrollo económico y desde una perspectiva occidental, que enmarcaba el conjunto de las reformas del gobernante en su deseo de abrir Rusia a Occidente. La otra gran monarca Catalina II, también impulsó el papel moneda ruso ya con el desarrollo paralelo de la banca central, no sin el hecho de reconocer que el rublo estuvo representado por periodos que en orden distinguen el uso del rublo de plata, el rublo de cobre, hasta la posterior aparición del credit ruble.

Durante la Unión Soviética el análisis se ha hecho sobre todo abarcando su estudio desde los enfoques que consideran su neutralidad o endogeneidad y de su influencia en las diferentes crisis económicas. La institucionalidad de la moneda ha tenido un desarrollo muy acorde a la visión tradicional de los medios de pago de la Europa Occidental, con relación di- 
recta a su acuñación en oro y otros metales. En la modernidad se ha asociado al desarrollo de la actividad bancaria y a la emisión del papel moneda con estabilidad económica, que en el caso de Rusia, generó tasas de productividad alcanzadas por favorecimientos desde la política estatal a la industrialización, que en el fondo notaban poca mejora de los procesos y un bajo grado de tecnificación. En épocas recientes, el país ha sufrido problemas en el manejo de la moneda relacionados con la disolución de la Unión Soviética y la adopción de la economía de mercado, que han llevado a etapas de crisis como la de 2008.

La historia económica puede nutrirse de la experiencia atípica de la moneda en Rusia, que sirve como ejemplo claro de un comportamiento cíclico y que puede analizarse en dos grandes estadios: un estadio en el que la creación de la moneda nacional y de la banca central se circunscriben como procesos propios de imitación o de homogeneización a la manera de las sociedades occidentales (subdivisión de los agregados monetarios y de sus unidades rublo-kopek, relación directa con algunos metales, etc.); un segundo estadio incierto y menos dependiente de las políticas monetarias durante la Unión Soviética, donde la moneda sufre un proceso de expansión a la manera de una unión monetaria, con mayor importancia del oro (importancia que fue reconocida por el mismo Stalin), gracias al estímulo de la exploración de yacimientos y de su producción, que sin embargo, descuidó el manejo de los agregados para evitar su pérdida de poder adquisitivo, lo que contribuyó al colapso de la Unión Soviética.

En este sentido, un manejo cuidadoso de la moneda como institución, supone soportarse en la experiencia que sobre ella han acumulado las sociedades occidentales. Parece ser que la institucionalidad de la moneda como elemento no sólo identitario, sino además factor de firmeza económica, se ha conseguido con relación al rublo, en la adopción de políticas monetarias principalmente provenientes del pensamiento económico occidental, en comparación con el manejo menos ortodoxo de los recursos monetarios en la época socialista.

En nuestros contextos, pareciese quedar la idea de que el manejo monetario implica un cierto nivel de independencia de los propios Estados, por cuanto la experiencia de las naciones con bancas centrales fortalecidas y políticas monetarias atadas a patrones occidentales, permiten como herramienta una mayor estabilidad económica y una institucionalización de la moneda como valor social.

\section{Referencias}

Bain, K. \& Howells, P. (2009). Monetary economics policy and its theoretical basis, $2^{\text {nd }}$ ed. Plagrave-Mc Millan. https://doi.org/10.1007/978-1-137-01342-2

Bank of Russia. (2016). Monetary Policy Guidelines for 2017-2019, Moscow.

Berlin, I. (2012). Pensadores rusos. México DF: Fondo de Cultura Económica.

Billington, J. (2011). El icono y el hacha. Una historia interpretativa de la cultura rusa. Madrid: Ed. Siglo XXI.

Cecchetti, S. \& Schoenhotz, K. (2011). Money banking and financial markets. Nueva York: McGraw-Hill. 
Dabrowski, M. (1995), The reasons of the collapse of the ruble zone. Case studies and analyses, 58, http://www.case-research.eu/sites/default/files/publications/3460035_058e_0.pdf. https://doi.org/10.2139/ssrn.1312324

Dabrowski, M. (2016a. Currency crises in post-soviet economies. A never ending story? Russian Journal of Economics, 2, 302-326. https://doi.org/10.1016/j.ruje.2016.08.002

Dabrowski, M. (2016b). Collapse of the Ruble Zone and Its Lessons Post-Communist Transition and Monetary Disintegration CESifo Forum 4, December, pp. 1-9.

Dabrowski, M. \& Rostowski, J. (1995). What went wrong? The reasons for the failure of stabilization in Russia in 1992, Case Studies and Analyses, 44, http://www.case-research.eu/sites/ default/ files/publications/3459678_sa44_0.pdf.

Dolan, E. (1976). Austrian Economics as Extraordinary Science. En Edwin G. Dolan (Ed.). The Foundations of Modern Austrian Economics. Sheed and Ward, Inc, Liberty Fund, Inc. pp. 6-16.

Green T. (1983). El nuevo mundo del oro. Sus minas, sus mercados su política y sus inversiones. Barcelona: Planeta.

Kirchner, W. (1976). History of Russia. Summary of events from earliest Times with chronological table maps and charts. Barnes \& Noble Edition, $2^{\text {nd }}$ ed. New York.

Kluchevsky, O. (1911). A History of Russia. London: J.M. Dent \& Sons. Ltda. New York.

Lenin, V. (1981). De la vida económica de Rusia. Obras Completas. Cap 6. Moscú: Ed. Progreso.

Maisiev, S. (2012). Istoria Centralnej bancov i bumashnij dienij. Centralnij bank rossiskoi federatsiyi.

Mavor, J. (1914). An Economic History of Rusia. Londres: J. M. Dentt \& Sons Limited.

McKinnon, R. (1963). Optimum Currency Areas. American Economic Review, 53, 717-725.

Mundell, R. (1961). A Theory of Optimum Currency Areas. American Economic Review, 51, 657665.

Orlowski, L. (1993). Indirect Transfers in Trade among Former Soviet Union Republics: Sources, Patterns, and Policy Responses in the PostSoviet Period, WCOB Faculty Publications, 198. https://doi.org/10.1080/09668139308412138

Owen, T. (1989). A standard Ruble of account for russian business history, 1769-1914: A note. Journal of Economic History, 49(3), 699-706. https://doi.org/10.1017/S0022050700008834

Pares, B. (1944). A History of Russia. Nueva York: Ed. Alfred A. Knopf.

Pla, I. (2003). Cambios Institucionales en la Economía Rusa: de las reformas de mercado a la consolidación monetaria, Revista de Economía Institucional, 5(8), 66-91.

Pikhoya, G. (2003). Gold Mining in Russia. The LBMA Precious Metals Conference 2003, Lisbon. En: http://www.lbma.org.uk/assets/3d_pikhoyalbmaconf2003.pdf

Seljak, A. (2012). Nicht Immer rollte der Rubel (German Edition). Das russiche Geld und Kreditsystem vom Kiever Reis bis 1897.

Trenin, D. (2016). Should we fear Russia? Cambridge, UK: Polity Press. 
Vernadsky, G. (1930). A History of Russia. New Haven. Yale University Press. London.

Vera, H. (2018). Análisis del desarrollo de la moneda rusa: la historiografía bizantina y eslavista del rublo. Cuadernos Medievales, 24, 19-34.

Vilariño, A (2001). Turbulencias financieras y riesgos de mercado. Madrid: Ed. Prentice Hall.

Zhukov, S. (1993). Monetary Aspects of Russian Transition. The United Nations University. WIDER. Working Papers, 106. 


\section{Anexo}

Tasa de cambio Dólar-Rublo, 1792-2015

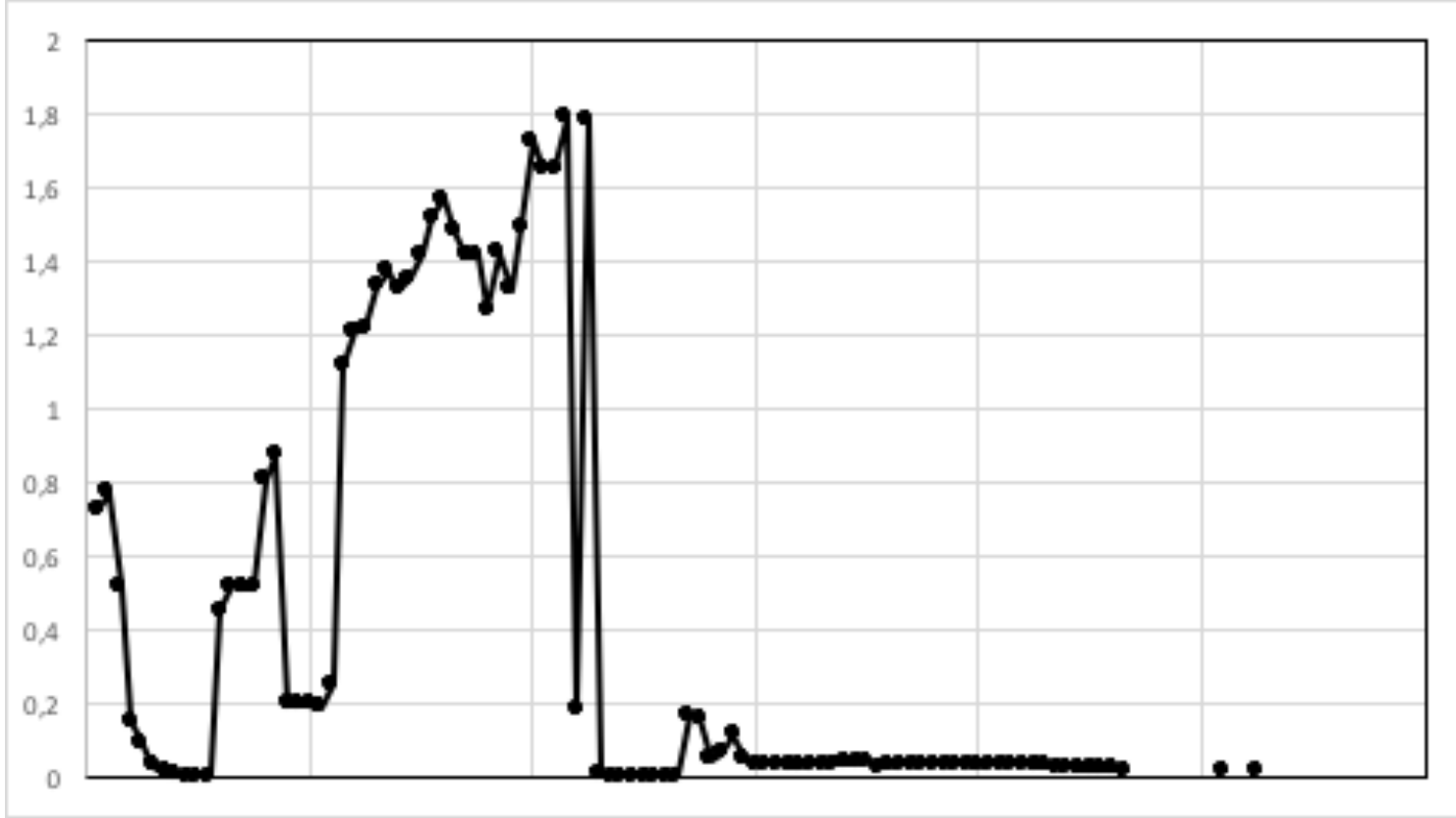

Fuente: elaboración propia con base en los datos de https://anaga.ru//analytcal-info/2/4.htm

Tasa de cambio Rublo-Dólar 1792-2015

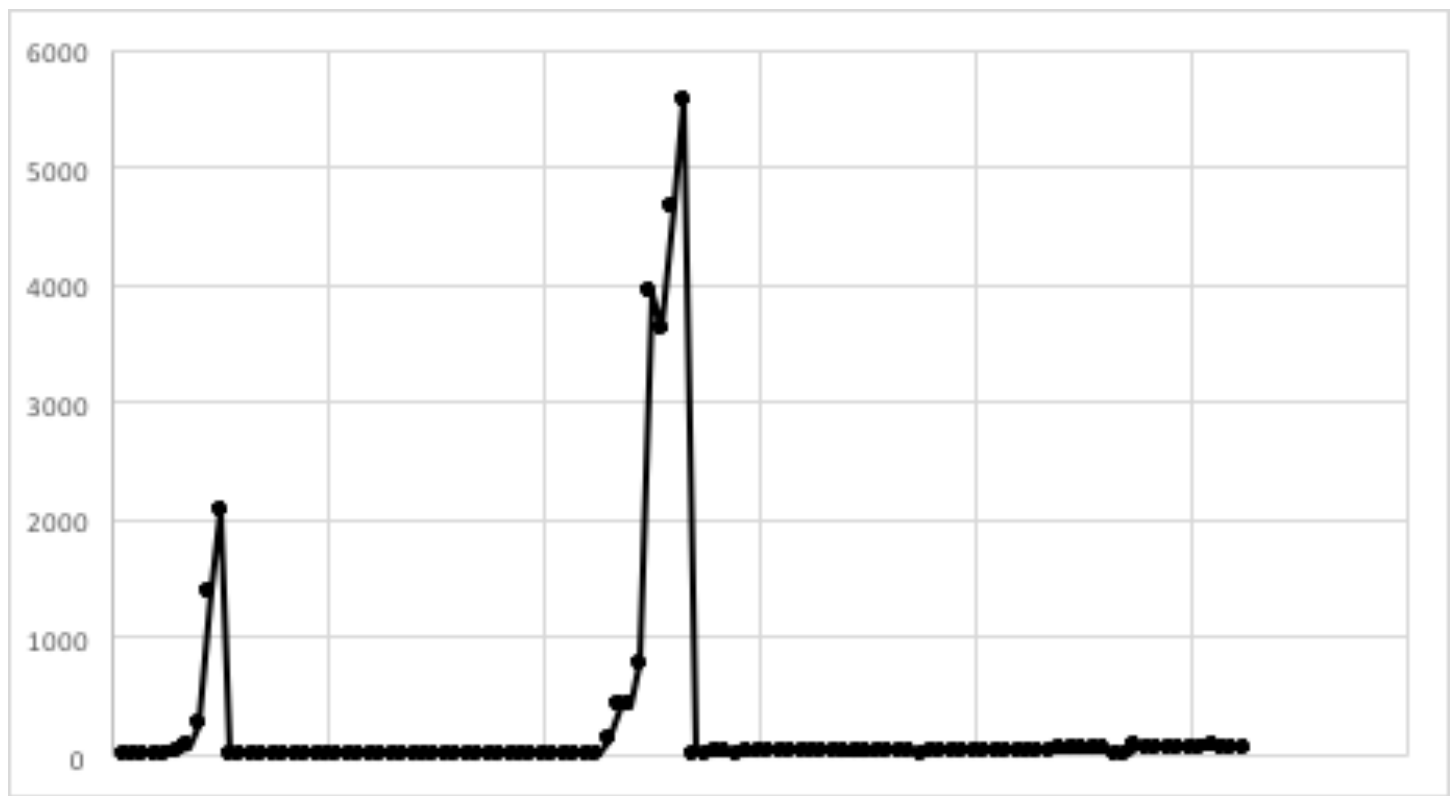

Fuente: elaboración propia con base en los datos de https://anaga.ru//analytcal-info/2/4.htm

tiempo\&economía

Vol. 6 N.․ 2 - Julio - Diciembre del 2019

p. 35 